\title{
O corpo da mulher com deficiência intelectual nos discursos em pesquisas acadêmicas
}

\author{
The body of the woman to be intellectually disabled in the speeches in \\ academic research
}

El cuerpo de la mujer intelectualmente discapacitada en los discursos en la investigación académica

\author{
Alcilene Rodrigues Pereira \\ Mestra pela Universidade Federal de Ouro Preto, Ouro Preto, Minas Gerais, Brasil. \\ alcilenerodrigues87@gmail.com \\ ORCID - https://orcid.org/0000-0001-5118-6456 \\ Carla Mercês da Rocha Jatobá Ferreira \\ Professora doutora na Universidade Federal de Ouro Preto, Ouro Preto, Minas Gerais, Brasil. \\ carlajatobaferreira@gmail.com \\ ORCID - https://orcid.org/0000-0001-9888-7743 \\ Margareth Diniz \\ Professora doutora na Universidade Federal de Ouro Preto, Ouro Preto, Minas Gerais, Brasil. \\ dinizmargareth@gmail.com \\ ORCID - https://orcid.org/0000-0001-6852-5389
}

Recebido em 28 de julho de 2020

Aprovado em 6 de outubro de 2020

Publicado em 25 de novembro de 2020

\section{RESUMO}

O artigo visa compreender como as pesquisas acadêmicas expressam em suas produções discursos acerca dos corpos das mulheres ditas com deficiência intelectual. Para tanto, realizou-se um levantamento bibliográfico entre os anos de 2003 e 2020, nos bancos de dados da Biblioteca Digital Brasileira de Teses e Dissertações (BDTD-IBICT), no Banco de Teses e Dissertações da Coordenação de Aperfeiçoamento de Pessoal de Nível Superior (CAPES), no Cientific Eletronic Library Online (Scielo) e no GT 15 da Associação Nacional de Pós-Graduação e Pesquisa em Educação - ANPED. Os descritores usados para tal busca foram: deficiência intelectual, gênero, corpo e sexualidade. A metodologia utilizada para análise dos dados encontrados circunscreveu-se em organizações temporais, por meio das mesmas categorias elencadas para a busca. Como resultados da pesquisa, expostos neste artigo, destaca-se a ausência de pesquisas que discutam a relação corpo, gênero e sexualidade das mulheres consideradas com deficiência intelectual. Conclui-se que as produções discursivas reiteradas nas inúmeras pesquisas sobre os corpos das mulheres ditas com deficiência intelectual indicam que seus corpos são desconsiderados, evidenciando assim, a invisibilização dessas mulheres, bem como a reprodução de saberes que as fazem permanecer como corpos deficientes.

Palavras-chave: Mulheres; Deficiência intelectual; Corpo. 
http://dx.doi.org/10.5902/1984686X48398

\section{ABSTRACT}

The article aims to understand how academic research expresses in their productions speeches about the bodies of women said to have intellectual disabilities.

To this end, a bibliographic survey was carried out between 2003 and 2020, in the databases of the Brazilian Digital Library of Theses and Dissertations (BDTD-IBICT), in the Bank of Theses and Dissertations of the Coordination for the Improvement of Higher Education Personnel (CAPES), the Cientific Eletronic Library Online (SciELO) and GT 15 of the National Association of Graduate Studies and Research in Education - ANPED. The descriptors used for this search were: intellectual disability, gender, body and sexuality. The methodology used to analyze the data found was limited to temporal organizations, using the same categories listed for the search. As a result of the research, exposed in this article, the absence of research that discusses the relationship between body, gender and sexuality of women considered with intellectual disabilities stands out. It is concluded that the discursive productions reiterated in the innumerable researches on the bodies of women said to have intellectual disabilities indicate that their bodies are disregarded, thus evidencing the invisibility of these women, as well as the reproduction of knowledge that makes them remain disabled bodies.

Keywords: Women; intellectual disability; body.

\section{RESUMEN}

El artículo tiene como objetivo comprender cómo la investigación académica expresa en sus producciones discursos sobre los cuerpos de mujeres que se dice que tienen discapacidad intelectual. Para ello, se realizó un levantamiento bibliográfico entre 2003 y 2020, en las bases de datos de la Biblioteca Digital Brasileña de Tesis y Disertaciones (BDTD-IBICT), en el Banco de Tesis y Disertaciones de la Coordinación para el Perfeccionamiento del Personal de Educación Superior. (CAPES), la Cientific Eletronic Library Online (Scielo) y GT 15 de la Asociación Nacional de Posgrado e Investigación en Educación - ANPED. Los descriptores utilizados para esta búsqueda fueron: discapacidad intelectual, género, cuerpo y sexualidad. La metodología utilizada para analizar los datos encontrados se limitó a organizaciones temporales, utilizando las mismas categorías enumeradas para la búsqueda. Como resultado de la investigación, expuesta en este artículo, se destaca la ausencia de investigaciones que discutan la relación entre cuerpo, género y sexualidad de mujeres consideradas con discapacidad intelectual. Se concluye que las producciones discursivas reiteradas en las innumerables investigaciones sobre los cuerpos de mujeres con discapacidad intelectual señalan que sus cuerpos son desatendidos, evidenciando así la invisibilidad de estas mujeres, así como la reproducción de conocimientos que las hace seguir siendo cuerpos discapacitados.

Palabras clave: Mujeres; discapacidad intelectual; cuerpo. 


\section{O Estado da arte e a produção dos corpos da mulher considerada deficiente intelectual}

Ao realizarmos o levantamento bibliográfico, para compor o referido Estado da arte visamos tanto a compreensão e a avaliação do conhecimento divulgado sobre a produção dos corpos das mulheres consideradas com deficiência intelectual, quanto a demarcação temporal das produções acadêmicas, analisando categorias e a multiplicidade de enfoques e perspectivas apontadas nas pesquisas.

Entendemos que o Estado da arte, como modalidade de pesquisa, permite a circunscrição de um campo de saber relativo ao objeto de estudo, apontando os percursos, os percalços e os aspectos privilegiados na pesquisa. Acrescentamos às características citadas outras elencadas por Ferreira (2002), referentes às motivações que guiam pesquisadores e pesquisadoras para realizarem tal modalidade de pesquisa:

[...] sustentados e movidos pelo desafio de conhecer o já construído e produzido para depois buscar o que ainda não foi feito, de dedicar cada vez mais atenção a um número considerável de pesquisas realizadas de difícil acesso, de dar conta de determinado saber que se avoluma cada vez mais rapidamente e de divulgá-lo para a sociedade (FERREIRA, 2002, p. 259).

O presente artigo é parte de uma pesquisa de mestrado e aqui recortamos e sistematizamos o Estado da arte, por meio de um levantamento realizado em bancos de dissertações e teses disponíveis na Biblioteca Digital Brasileira de Teses e Dissertações (BDTD-IBICT), no Banco de Teses e Dissertações da Coordenação de Aperfeiçoamento de Pessoal de Nível Superior (CAPES), no Cientific Eletronic Library Online (Scielo) e no GT 15 da Associação Nacional de Pós-Graduação e Pesquisa em Educação - ANPED, que trata da Educação Especial. A partir desse levantamento, buscamos compreender a produção dos corpos de mulheres consideradas com deficiência intelectual nos discursos expressos nas pesquisas acadêmicas, no período entre 2003 e 2020

Ao considerarmos a importância de refletir sobre saberes produzidos pelos discursos acadêmicos no que tange às representações de corpos de mulheres ditas com deficiência intelectual, estabelecemos considerações acerca das produções analisadas. A partir dos descritores deficiência intelectual, gênero, corpo e sexualidade, recortamos trabalhos que envolviam apenas os discursos acerca da deficiência intelectual, eixo da pesquisa, nomeado como deficiência intelectual e sexualidade. 
http://dx.doi.org/10.5902/1984686X48398

Longe de ser a natureza que reprime o sujeito com deficiência, é a cultura da normalidade que relata quais performances são desejadas ou não para determinado contexto social. Gaudenzi e Ortega (2016) defendem que os discursos que envolvem a ideia de competência no conceito de deficiência expõem a complexa situação de delimitar quais capacidades e habilidades são necessárias em um sujeito e quem tem o poder de estabelecê-las. A esse respeito, a cultura e os discursos são processos de contínua produção, atualização e transformação de modelos simbólicos, por meio de práticas individuais e coletivas, em contextos historicamente específicos e socialmente estruturados.

Os discursos constituídos ao longo do tempo acerca do sujeito dito com deficiência ainda permanecem em nosso contexto social. Com maior ou menor força, legitimidade ou hegemonia, todas as visões possuem posições no campo, cristalizadas por meio dos arranjos duradouros e transmissíveis de constituições e práticas de acordo com os pensamentos, ações e sentimentos de determinado grupo social.

A realidade social se estrutura de modo não linear, em jogos de linguagens e jogos de verdades que visam conquistar um consenso que os legitime. Todo discurso social pode questionar-se, desconstruir-se e modificar-se. Por meio do jogo da linguagem, os discursos se modificam, se validam, se questionam, alteram criações e recriações permanentemente. A linguagem, longe de ser algo homogêneo, configura-se em um espaço múltiplo não fixo. Então, construídos socialmente, todo discurso e prática social podem ser questionadas e descontruídas (BROGNA, 2009).

A primeira parte da investigação resultou na compilação de 59 trabalhos acadêmicos, abrangendo outras deficiências além da intelectual. Destacamos 32 (trinta e dois) trabalhos em que a deficiência intelectual foi abordada e adotada como recorte. Estes serão os trabalhos analisados por nós.

Quanto ao referencial teórico adotado pelos(as) autores(as) em tais pesquisas, podemos destacar a menção aos pesquisadores Goffman (1988), Glat (1989) e Débora Diniz (2007), citados em diferentes pesquisas. Notamos que nas pesquisas de Santos (2007), Santos e Osório (2010) e Silva (2015) os estudos de Michel Foucault (1985) foram utilizados para análise do discurso. Enquanto Souza (2014) ateve-se às noções das representações propostas por Alain Giami (2004).

Quanto à metodologia, encontramos na entrevista o principal instrumento para a coleta de dados, sendo utilizada em 15 dos 32 trabalhos. Lüdke e André (2003) apontam 
http://dx.doi.org/10.5902/1984686X48398

que "a entrevista é uma das principais técnicas de trabalho em quase todos os tipos de pesquisa utilizadas nas ciências sociais" (LÜDKE; ANDRÉ, 2003, p. 33-34). A esse respeito, as autoras seguem dizendo que "a grande vantagem da entrevista sobre outras técnicas é que ela permite a captação imediata e corrente da informação desejada, praticamente com qualquer tipo de informante e sobre os mais variados tópicos" (LÜDKE, 2003, p. 34).

A análise documental, combinada a outras técnicas, como observação, questionário, grupo focal e oficinas, obteve destaque em alguns trabalhos. Ao longo do artigo serão apresentados os resultados obtidos por estas pesquisas e para fins de organização, obedeceremos à ordem temporal dos trabalhos encontrados. No decorrer da exposição de tais achados, faremos a discussão que nos interessa, destacando aspectos que traduzem a concepção e representação acadêmica sobre o corpo das mulheres com deficiência intelectual.

\section{Pesquisas realizadas entre 2003 e 2007}

Neste item, discutimos resultados obtidos nas pesquisas e artigos localizados no interstício 2003 a 2007. É importante destacar que usamos a nomenclatura deficiência intelectual, como foi preconizada pela ONU em 1995, embora a nomenclatura usada nas pesquisas aqui relacionadas usa deficiência mental, como vamos mostrar no quadro abaixo.

A Tabela 1 evidencia o conteúdo encontrado nos 32 trabalhos sobre a deficiência intelectual, corpo e sexualidade na BDTD, CAPES, Scielo e ANPED entre 2003 e 2007.

Tabela 1 - Deficiência intelectual, corpo e sexualidade - Período 2003 e 2007

\begin{tabular}{|c|c|c|}
\hline TÍTULO & AUTOR (ANO) & METODOLOGIA \\
\hline $\begin{array}{l}\text { Sexualidade da pessoa com } \\
\text { síndrome de Down. }\end{array}$ & 1) Castelão et al. (2003) & Estudo qualiquantitativo \\
\hline $\begin{array}{l}\text { Sexualidade e deficiência } \\
\text { mental: impacto de um programa } \\
\text { de orientação para famílias. }\end{array}$ & 2) Amaral (2004) & Estudo qualitativo \\
\hline $\begin{array}{l}\text { Sexualidade e deficiência } \\
\text { mental: revisando pesquisas. }\end{array}$ & 3) Pinheiro (2004) & Revisão \\
\hline $\begin{array}{l}\text { Entre o desejo e o medo de ver o } \\
\text { filho adolescer: narrativas de pais } \\
\text { de adolescentes com deficiência } \\
\text { mental. }\end{array}$ & 4) Bastos (2005) & Estudo qualitativo \\
\hline
\end{tabular}


http://dx.doi.org/10.5902/1984686X48398

Tabela 1 - Deficiência intelectual, corpo e sexualidade - Período 2003 e 2007

\begin{tabular}{|c|c|c|}
\hline $\begin{array}{l}\text { Sexualidade e o adolescente } \\
\text { com deficiência mental: uma } \\
\text { revisão bibliográfica. }\end{array}$ & $\begin{array}{l}\text { 5) Bastos e Deslandes } \\
(2005)\end{array}$ & Revisão \\
\hline $\begin{array}{l}\text { A qualidade de vida de adultos } \\
\text { com deficiência mental leve, na } \\
\text { percepção destas pessoas e na } \\
\text { de seus cuidadores. }\end{array}$ & 6) Zeoti (2005) & Estudo qualiquantitativo \\
\hline $\begin{array}{l}\text { Identidade feminina e } \\
\text { sexualidade na concepção de } \\
\text { mulheres com síndrome de } \\
\text { Down: educação sexual como } \\
\text { caminho para a construção de } \\
\text { maior autonomia. }\end{array}$ & 7) Uzêda (2006) & Estudo qualitativo \\
\hline $\begin{array}{l}\text { A sexualidade como aspecto } \\
\text { inclusivo: uma proposta de } \\
\text { intervenção para pais e } \\
\text { professores de Jovens com } \\
\text { Deficiência Mental. }\end{array}$ & 8) Albuquerque (2007) & Estudo qualitativo \\
\hline $\begin{array}{l}\text { Percepções de jovens com } \\
\text { Síndrome de Down sobre } \\
\text { relacionar-se amorosamente. }\end{array}$ & 9) Luiz e Kubo (2007) & Relato de pesquisa \\
\hline $\begin{array}{l}\text { Educação sexual de pessoas } \\
\text { com deficiência mental. }\end{array}$ & 10) Pieczkowski (2007) & Ensaio teórico \\
\hline $\begin{array}{l}\text { Sexualidade da pessoa com } \\
\text { deficiência mental: entre } \\
\text { discursos de verdade e a } \\
\text { possibilidade de outras práticas } \\
\text { de si. }\end{array}$ & 11) Santos (2007) & Estudo qualitativo \\
\hline
\end{tabular}

Fonte: Elaborado pelas autoras a partir de dados da BDTD-IBICT, Banco de Teses e Dissertações da CAPES, Scielo e GT 15 - ANPED (2020).

Castelão, Shiavo e Jurberg (2003) analisaram a opinião de pais e profissionais sobre a sexualidade de pessoas com Síndrome de Down (SD), identificando como o grupo percebe a sexualidade. A aplicação de questionários e a realização dos grupos focais ocorreram durante cursos patrocinados pela Federação Brasileira das Associações de Síndrome de Down, em uma cidade de cada região do país: na região Sudeste, em Vitória, na região Nordeste, em Salvador, na região Sul, em Porto Alegre, e na região Norte, em Manaus. Os resultados evidenciaram que os pais infantilizam os filhos e os profissionais se encontram despreparados para orientar sexualmente pessoas com SD.

Em seu artigo, Pinheiro (2004) mostra uma revisão das pesquisas publicadas desde o ano de 1971, envolvendo deficiência mental ${ }^{1}$ e sexualidade. A autora constatou que o 
http://dx.doi.org/10.5902/1984686X48398

tema tem sido ignorado pela falta de instrumentos para investigar o fenômeno na realidade brasileira. Pinheiro (2004) defende ainda que as pessoas com deficiência mental possuem pouco conhecimento e experiência sexual e afirma que pais e profissionais não lhes fornecem uma educação sexual significativa. A pesquisadora aponta a necessidade de adaptar instrumentos para o conhecimento da realidade e para o desenvolvimento de programas de educação sexual.

Amaral (2004), em pesquisa de mestrado, identificou variáveis capazes de influenciar modificações nos repertórios de conceitos e comportamentos de oito familiares (dois pais, cinco mães e uma responsável) de adolescentes e adultos com deficiência mental, a partir de um Programa de Orientação Sexual. A realização de entrevistas estruturadas, em instituições e/ou escolas especializadas, permitiu que a autora colhesse dados para caracterizar e examinar possíveis mudanças de repertório. As mudanças observadas na pesquisa foram favoráveis em termos de desenvolvimento da sexualidade da pessoa com deficiência mental.

Bastos (2005), em sua tese, analisou as perspectivas dos pais de jovens deficientes mentais sobre o adolescer e sobre as expressões da sexualidade de seus filhos. Ao entrevistar pais que tinham seus filhos atendidos no Instituto Fernandes Figueira, pertencente a Fundação Oswaldo Cruz, percebeu a incerteza em reconhecer o direito ao exercício da sexualidade dos filhos. Destacou certa hesitação na concessão de uma maior liberdade aos filhos, já que os pais oscilam entre a aspiração e o medo de ver o filho crescer. Posteriormente, Bastos e Deslandes (2005), com o objetivo de discutir a sexualidade de adolescentes com deficiência mental e as repercussões familiares do adolescente, realizaram pesquisa bibliográfica na base de dados da Biblioteca Virtual Bireme. Seus dados mostraram que, com a chegada da adolescência, os pais se deparam com novos desafios para a integração social dos filhos, especialmente com o despertar sexual.

Em sua dissertação, Zeoti (2005) apontou para a opinião de adultos com deficiência mental, em relação à qualidade de vida e à opinião dos cuidadores. Avaliou a sobrecarga gerada na vida desses cuidadores pelo cuidar das pessoas deficientes frequentadoras de um Centro de Educação Especial na cidade de Ribeirão Preto. As pessoas com deficiência responderam a um instrumento que avalia a qualidade de vida (WHOQOL- Bref) e a uma entrevista estruturada. Os cuidadores responderam, além desses dois instrumentos, a uma escala que avalia a sobrecarga ao cuidar, a "Burden Interview". A autora observou que pessoas com deficiência se apresentam satisfeitas e seus cuidadores não se sentem 
http://dx.doi.org/10.5902/1984686X48398

sobrecarregados, entretanto, há dúvidas e receios com relação à sexualidade das pessoas com deficiência mental.

Ao contemplar as vozes femininas, Uzêda (2006) analisou em sua dissertação concepções de mulheres com Síndrome de Down no que se refere à identidade e sexualidade femininas, e se os estigmas construídos socialmente relacionados à identidade, reforçando ideias de incapacidade e imaturidade atribuídas à mulher com deficiência mental. Por meio de oficinas com três mulheres com Síndrome de Down, frequentadoras da Sociedade Pestalozzi, no Estado da Bahia, evidenciou-se a desinformação e concepções distorcidas sobre corpo e sexualidade por parte dessas mulheres, além da diferenciação dos papéis sexuais em função do gênero.

Fundamentada na abordagem sociohistórica, a autora concluiu que a limitação cognitiva, leve ou moderada, não impossibilita a efetivação de programas de educação sexual, entendendo que a sexualidade é presente durante todas as fases do desenvolvimento humano. Ao recorrer a autores(as) como Ciampa (1997), Bourdieu (2003), Vigotsky $(1989,1997)$ e Glat (1996), a pesquisadora concluiu que a sexualidade na pessoa com deficiência mental, da maneira como tem sido pensada e tratada pela sociedade, constitui-se como fator impeditivo de uma efetiva inclusão social, favorecendo a perpetuação de estigmas. (o parágrafo foi dividido conforme solicitação do avaliador)

Albuquerque (2007), em pesquisa de mestrado, buscou compreender concepções de pais e professores acerca da sexualidade dos filhos e alunos com deficiência mental. $O$ estudo foi realizado numa escola especial na cidade de São Paulo. Após entrevistas semiestruturadas, a autora elaborou um curso como proposta de intervenção, fundamentando-se em autores como França Ribeiro (1995, 2001) e Maia (2006). A autora concluiu em seu estudo que houve a ampliação das reflexões sobre o tema sexualidade deficiência mental, uma percepção da importância da sexualidade na vida das pessoas com deficiência mental, bem como uma atenção e respeito maior por seus interesses e necessidades afetivas-sexuais.

Pieczkowski (2007), considerando que a sexualidade na deficiência mental ainda é um tabu e provoca desconforto para a sociedade, causando confusões e discriminações, desenvolveu um projeto em escola especial que atende pessoas com deficiência mental. $\mathrm{O}$ artigo ressalta a importância de conscientizar a sociedade sobre o fato de que as pessoas com deficiência mental não são assexuadas, tampouco têm sua sexualidade incontrolável. A autora concluiu ser imprescindível instrumentalizar profissionais e familiares para tomar 
http://dx.doi.org/10.5902/1984686X48398

atitudes coerentes ao se depararem com manifestações de sexualidade de alunos ou filhos considerados ou não deficientes.

Luiz e Kubo (2007), visando descobrir as percepções de jovens com Síndrome de Down sobre relacionamentos amorosos, entrevistou, individualmente, duas mulheres e três homens com Síndrome de Down, com idade superior a 15 anos e moradores da região sul do país. Fundamentando-se em autores como Franco (1991), Glat (1993) e Giami (2004), o artigo evidenciou que percepções dos jovens com Síndrome de Down sobre relacionamentos amorosos não diferem daquelas de jovens sem síndrome e, muito provavelmente, são desenvolvidas pelas oportunidades de se comportarem efetivamente sob contingências que favoreçam comportamentos amorosos.

Em sua dissertação, Santos (2007) adotou, como fundamentação teórica, os estudos de Foucault para investigar discursos de verdade sobre a sexualidade da pessoa com deficiência mental. A autora analisou duas teses e oito dissertações a partir dos pressupostos foucaultianos. Suas análises indicaram que familiares e profissionais que atuam com o grupo pressupõem que pessoas deficientes mentais são seres assexuados, pois, quando adultos, não demonstram desejo. Em outro extremo, são pessoas que possuem uma sexualidade desmensurada.

\section{Pesquisas desenvolvidas entre os anos 2008 e 2013}

Neste item, discutiremos resultados obtidos nas pesquisas e artigos localizados no interstício 2008 a 2013. Percebemos nesses trabalhos a ausência de indicativos que demonstrem a capacidade de mulheres ditas com deficiência intelectual para conduzir seu corpo e sexualidade.

Tabela 2 - Deficiência intelectual, corpo e sexualidade - Período entre 2008 e 2013

\begin{tabular}{|l|l|l|}
\hline \multicolumn{2}{|c|}{ TíTULO } & \multicolumn{1}{c|}{ AUTOR (ANO) } \\
\hline $\begin{array}{l}\text { Habilidades de autoproteção } \\
\text { acerca do abuso sexual em } \\
\text { mulheres com deficiência } \\
\text { mental. }\end{array}$ & 12) Barros et al. (2008) & Relato de pesquisa \\
\hline $\begin{array}{l}\text { Práticas discursivas e o } \\
\text { silenciamento do doente mental: } \\
\text { sexualidade negada? }\end{array}$ & 13) Miranda et al. (2008) & Estudo qualitativo \\
\hline
\end{tabular}


http://dx.doi.org/10.5902/1984686X48398

Tabela 2 - Deficiência intelectual, corpo e sexualidade - Período entre 2008 e 2013

\begin{tabular}{|l|l|l|}
\hline $\begin{array}{l}\text { Apropriação de práticas sociais } \\
\text { relativas à sexualidade por } \\
\text { jovens adultos com diagnóstico } \\
\text { de deficiência intelectual. }\end{array}$ & Estudo qualitativo \\
\hline $\begin{array}{l}\text { A sexualidade na deficiência } \\
\text { mental. }\end{array}$ & 15) Almeida (2010) & \\
\hline $\begin{array}{l}\text { Saber e prática na constituição } \\
\text { da sexualidade da pessoa com } \\
\text { deficiência mental. }\end{array}$ & 16) Santos e Osório (2010) & Estudo qualitativo \\
\hline $\begin{array}{l}\text { Questões invisíveis e as } \\
\text { histórias contadas por jovens: } \\
\text { deficiência intelectual e } \\
\text { vulnerabilidade ao HIV/AIDS. }\end{array}$ & 17) Sodelli (2010) & \\
\hline $\begin{array}{l}\text { Sexualidade e vulnerabilidade } \\
\text { social de pessoas com } \\
\text { transtornos } \\
\text { atendidas em serviços } \\
\text { públicos de saúde mental no } \\
\text { Brasil. }\end{array}$ & Estudo qualitativo \\
\hline $\begin{array}{l}\text { Sexualidade e deficiência } \\
\text { intelectual: narrativas de pais de } \\
\text { adolescentes. 19) Bastos e Deslandes (2012) }\end{array}$ & Estudo qualitativo \\
\hline $\begin{array}{l}\text { Sexualidade na deficiência } \\
\text { intelectual: umaanálise de } \\
\text { percepções de mães de } \\
\text { adolescentes especiais. }\end{array}$ & 20) Littig et al. (2012) & \\
\hline $\begin{array}{l}\text { Mulheres com deficiência } \\
\text { intelectual e esterilização } \\
\text { involuntária. Dequem é esse } \\
\text { corpo? 21) Régis (2013) }\end{array}$ & Estudo qualitativo \\
\hline
\end{tabular}

Fonte: Elaborado pelas autoras a partir de dados da BDTD-IBICT, Banco de Teses e Dissertações da CAPES, Scielo e GT 15 - ANPED (2020).

Barros, Williams e Brino (2008) entrevistaram seis mulheres frequentadoras de uma escola especializada no interior paulista, com o objetivo de investigar as habilidades de proteção contra abusos sexuais. As autoras constataram que as participantes não tinham um repertório de habilidades de autoproteção adequado para se protegerem de situações potencialmente abusivas do ponto de vista sexual. De acordo com a pesquisa, a incapacidade de discriminar situações de risco confirma a vulnerabilidade quanto ao abuso sexual, tornando necessária a formação de programas de prevenção para mulheres que apresentam déficit no repertório de habilidades de autoproteção. 
http://dx.doi.org/10.5902/1984686X48398

Para compreender as apropriações de práticas sociais quanto à sexualidade em aulas de Orientação Sexual na Educação de Jovens e Adultos, em instituição especial, Morales (2008) desenvolveu pesquisa de mestrado com dois grupos de adolescentes e jovens adultos com deficiência intelectual. A autora evidencia em sua pesquisa que os discentes formaram um grupo heterogêneo em relação à apropriação de conceitos sobre sexualidade. Constatou-se que os alunos, mesmo tendo poucas experiências de participação em grupos sociais além da escola, apropriaram-se de práticas sociais relativas à sexualidade, construídas histórica e coletivamente.

Miranda, Furegato e Azevedo (2008) investigaram as representações sociais dos profissionais enfermeiros sobre a sexualidade do doente mental. Com tal finalidade, utilizaram recurso técnico-metodológico denominado Técnica de Investigação em Situações Cotidianas (TSC), aplicado aos 17 enfermeiros que trabalhavam em serviços psiquiátricos de Ribeirão Preto (SP). Os autores verificaram que o profissional enfermeiro nega a sexualidade desse grupo, como uma forma de silêncio, estabelecendo limites para a censura sobre o assunto. Ao silenciar a sexualidade do doente mental, cumprem as determinações do estatuto profissional, que é ir ao encontro das expectativas institucionais e sociais.

Almeida (2010) destaca, em artigo, que a sexualidade na deficiência mental é pouco discutida e permeada de mitos, preconceitos e tabus. Na busca por perceber conhecimentos, necessidades e sentimentos de pessoas deficientes mentais, entrevistou jovens com este diagnóstico e alunos de escola pública. Por meio da análise qualitativa das entrevistas, constatou que as(os) jovens (duas raparigas e um rapaz) possuem conhecimentos precários sobre sua sexualidade, com experiências limitadas, e são, muitas vezes, privadas(o) de acesso à educação sexual adequada. A autora percebeu que os conhecimentos dos sujeitos sobre o assunto são insuficientes, incorretos e conclui: "as maiores dificuldades para as pessoas com deficiência mental viverem a sua sexualidade não são de ordem biológica, mas sim adaptativa" (ALMEIDA, 2010, p. 2).

Partindo dos resultados da análise de dez relatórios de pesquisa com fundamentação teórica nos estudos de Foucault, Santos e Osório (2010) evidenciaram a relação existente entre a produção do saber e as práticas cotidianas estabelecidas no meio social. A pesquisa é parte da dissertação que analisou produções acadêmicas sobre a sexualidade da pessoa com deficiência mental, relacionando-as a um projeto de orientação sexual desenvolvido com jovens com deficiência mental. Esse trabalho identificou um viés biologicista nas 
http://dx.doi.org/10.5902/1984686X48398

concepções de sexualidade e deficiência mental, condicionando a proposição de uma orientação sexual tida como antídoto para as manifestações da sexualidade desses sujeitos.

Sodelli (2010), em sua dissertação, analisou os aspectos que influenciam a vulnerabilidade ao HIV/AIDS de jovens com deficiência intelectual. Para tanto, foram entrevistados 14 jovens, acima de 18 anos, de duas instituições para jovens com deficiência intelectual na cidade de São Paulo. Os depoimentos apontaram importantes elementos de vulnerabilidade, tais como: nível de informação, vida sexual ativa, questões de gênero, relações afetivas e situações de violência. A autora evidenciou em sua pesquisa que a deficiência intelectual aparece como um dos elementos de vulnerabilidade, mas não é o fator determinante.

Considerando as altas taxas de prevalência de infecções sexualmente transmissíveis (IST) e HIV/AIDS detectadas em pessoas com transtornos mentais no Brasil, Barbosa (2011) destacou, em sua tese, representações dessas pessoas sobre sexualidade. Para essa autora, o autocuidado para a prevenção dos agravos sexualmente transmissíveis é realizado com dificuldades, o que decorre de diversos fatores objetivos e aspectos subjetivos, dentre estes o tabu que envolve a temática da sexualidade. Foram realizadas entrevistas abertas e em profundidade com 39 pessoas com transtornos mentais severos e persistentes, atendidas em serviços públicos de saúde mental no Brasil, sendo 22 homens e 17 mulheres, com idade entre 18 e 72 anos. A autora destaca que o contexto de exclusão social, além de dificultar o autocuidado em situações de violência sexual, mostrou-se favorecedor de comportamentos que contribuem para outras condutas de risco, como a de venda de sexo.

As concepções que mães de jovens com deficiência intelectual têm sobre a sexualidade de seus filhos, e como elas irão refletir na adoção de práticas de educação sexual, foram investigadas por Littig et al. (2012). As autoras entrevistaram 20 (vinte) mães de adolescentes com diagnóstico de deficiência intelectual, atendidos numa clínica escola localizada no Estado do Espírito Santo. As constatações do estudo dizem que as mães não reconhecem uma identidade sexual em seus filhos e, por conseguinte, não fornecem uma educação sexual, reproduzindo a concepção social e cultural que nega a existência da sexualidade quando associada à deficiência intelectual.

Bastos e Deslandes (2012), em artigo, buscaram compreender como os pais de adolescentes com deficiência mental experienciavam as manifestações sexuais de seus 
filhos. As autoras entrevistaram 14 pais de adolescentes diagnosticados com deficiência mental atendidos em uma unidade pública de saúde no Estado do Rio de Janeiro e concluíram que há preconceitos e desconhecimento sobre o tema. Para os pais de adolescentes do sexo masculino, a masturbação, a relação sexual e o medo de abuso sexual foram pontos destacados. Por outro lado, os pais das adolescentes evidenciaram as mudanças corporais e também a preocupação com o abuso sexual. As autoras ressaltam a necessidade de ampliação de debates com os(as) adolescentes com deficiência mental, com seus pais e com diversos setores da sociedade, com o objetivo de minimizar preconceitos a respeito da sexualidade da pessoa com deficiência e, dessa forma, buscar garantir seus direitos sexuais.

Régis (2013) investigou, em pesquisa de mestrado, discursos parentais sobre a esterilização involuntária de mulheres com deficiência intelectual. Foram identificadas vinte e três mulheres submetidas à esterilização e realizadas vinte e três entrevistas, com vinte e cinco familiares dessas mulheres. Com relação à seleção dos sujeitos para a pesquisa, não houve uma forma padronizada, já que cada instituição preferiu fazê-lo de maneira diferente. A pesquisa de Regis (2013) destacou a naturalização do procedimento de esterilização, por familiares e profissionais, ao se depararem com a necessidade de cessar a menstruação, evitar uma gravidez e protegê-las da violência sexual. O receio de ter um neto também com deficiência foi notado como um problema para essas famílias. As cirurgias foram efetivadas, em sua maioria, pelo Sistema Único de Saúde (SUS), mas a pesquisa ressalta que somente em três casos foram seguidos os trâmites legais, via autorização judicial. Constatou-se que os familiares tendem a presumir a incapacidade dessas mulheres de cuidar de uma criança, o que, segundo eles, incorreria em um ônus que seria assumir a responsabilidade pelo neto.

\section{Pesquisas desenvolvidas entre os anos 2014 e 2020}

Este último item aborda os resultados obtidos nas pesquisas e artigos localizados no interstício 2014 a 2020. Observamos nas pesquisas que estudos qualitativos preponderam nas teses, dissertações e publicações. Outro aspecto observado foi que 15 (quinze) trabalhos têm como foco a relação corpo, sexualidade e deficiência intelectual na perspectiva dos aspectos institucionais, familiares e sociais; 10 (dez) desses trabalhos tratam, prioritariamente, da deficiência intelectual em relação ao corpo e à sexualidade; o 
foco de 3 (três) trabalhos foi abuso sexual e HIV; e, por fim, apenas 1 (um) estudo contemplou esterilização e contracepção da mulher com deficiência.

Tabela 3 - Deficiência intelectual, corpo e sexualidade - Período entre 2014 e 2020

\begin{tabular}{|l|l|l|}
\hline \multicolumn{1}{|c|}{ TíTULO } & \multicolumn{1}{|c|}{ AUTOR (ANO) } & METODOLOGIA \\
\hline $\begin{array}{l}\text { Entrelace entre gênero, sexualidade } \\
\text { e deficiência: uma história feminina } \\
\text { de rupturas e empoderamento. }\end{array}$ & 22) Dantas et al. (2014) & Estudo qualitativo \\
\hline $\begin{array}{l}\text { Assexuados, libidinosos ou um } \\
\text { paradoxo sexual? Gênero - e } \\
\text { sexualidade em pessoas com } \\
\text { deficiência intelectual. }\end{array}$ & 23) Oliveira (2014) & Estudo qualitativo \\
\hline $\begin{array}{l}\text { Representações de profissionais da } \\
\text { saúde mental sobre sexualidade de } \\
\text { pessoas com transtornos mentais. }\end{array}$ & 24) Souza (2014) & Estudo qualitativo \\
\hline $\begin{array}{l}\text { Sexualidade e deficiência } \\
\text { intelectual: concepções, vivências e } \\
\text { o papel da educação. }\end{array}$ & 25) Vieira e Coelho (2014) & Estudo qualitativo \\
\hline $\begin{array}{l}\text { Opinião de professores sobre a } \\
\text { sexualidade e a educação sexual de } \\
\text { alunos com deficiência intelectual. }\end{array}$ & 26) Maia et al. (2015) & Estudo qualiquantitativo \\
\hline $\begin{array}{l}\text { Sexualidade e deficiências: dando } \\
\text { vozes aos adolescentes por meio de } \\
\text { oficinas pedagógicas. }\end{array}$ & 27) Paliarin (2015) & Estudo qualitativo \\
\hline $\begin{array}{l}\text { Cartografando a Gestão Familiar do } \\
\text { Sujeito narrado em uma Construção } \\
\text { anormalidade Intelectual: } \\
\text { Intersecções entre Gênero, } \\
\text { Sexualidade e "Deficiência". }\end{array}$ & 28) Silva (2015) & Estudo qualitativo \\
\hline $\begin{array}{l}\text { Produção do conhecimento sobre } \\
\text { sexualidade e deficiência } \\
\text { Intelectual e/ou síndrome de down. }\end{array}$ & 29) Rosa (2016) & Estudo qualitativo \\
\hline $\begin{array}{l}\text { Sexualidade e transtorno do } \\
\text { Espectro autista: relatos de } \\
\text { familiares. }\end{array}$ & 30) Vieira (2016) & Estudo qualitativo \\
\hline $\begin{array}{l}\text { Mulheres ditas com deficiência } \\
\text { intelectual: Limites e possiblidades } \\
\text { dos contextos inclusivos }\end{array}$ & 31) Pereira (2019) & Estudo qualitativo \\
\hline $\begin{array}{l}\text { Opiniões de mães e profissionais } \\
\text { sobre a sexualidade de } \\
\text { Pessoas com deficiência intelectual. }\end{array}$ & $\begin{array}{l}\text { 32) Gonçalves e Barbosa } \\
\text { (2020) }\end{array}$ & Estudo qualitativo \\
\hline
\end{tabular}

Fonte: Elaborado pelas autoras a partir de dados da BDTD-IBICT, Banco de Teses e Dissertações da CAPES, Scielo e GT 15 - ANPED (2020).

Souza (2014), em pesquisa de doutorado, questionou profissionais atuantes nos serviços de saúde mental da rede pública de Minas Gerais sobre o que pensam da sexualidade das pessoas com transtornos mentais. Os sujeitos da pesquisa formaram seis 
http://dx.doi.org/10.5902/1984686X48398

grupos focais com 54 profissionais de serviços públicos de saúde mental do referido Estado. As representações dos profissionais de saúde mental contribuem para a perpetuação de estigmas e preconceitos sobre a vivência plena da sexualidade de pessoas com transtornos mentais. A autora constatou a quase inexistência de ações de promoção da saúde sexual para as pessoas com transtornos mentais, bem como as limitações naquelas existentes, relacionadas ao despreparo dos participantes, advindo desde as formações profissionais.

Oliveira (2014) entrevistou professores, técnicos especialistas e funcionários da Associação de Pais e Amigos dos Excepcionais (APAE), numa cidade do interior paulista, e analisou os prontuários de atendimento dos matriculados. Concluiu com sua pesquisa de mestrado que os docentes e profissionais da APAE encaram a deficiência intelectual como sinônimo de falta, desvantagem e incapacidade, enquanto os discentes indicam que a deficiência intelectual é uma das múltiplas configurações do existir humano. Para os professores, a sexualidade dos alunos é descontrolada e perigosa, por outro lado, os alunos assumem a sexualidade como uma maneira de suavizar a diferença, em relação aos que não possuem deficiência intelectual, como um prazer que nada tem de anormal.

Dantas, Silva e Carvalho (2014) analisaram o processo de empoderamento e o exercício da autoadvocacia na vida de uma jovem deficiente intelectual. O movimento da autoadvocacia se fundamenta no princípio de que o próprio indivíduo tem o direito e o dever de participar de decisões sobre a sua pessoa. A pesquisa adota a metodologia de história oral e contribui para o campo de investigação sobre deficiências, gênero e sexualidade a partir da visibilidade da história de vida de uma mulher com deficiência intelectual. As autoras evidenciaram que a superação do rótulo de incapacitante foi condição fundamental para que ela se reconhecesse como uma mulher sexuada, com a capacidade de tomar decisões e viver seus desejos.

Vieira e Coelho (2014) pesquisaram as concepções e vivências de sexualidade de jovens com deficiência intelectual por meio de entrevistas individuais com 13 jovens de uma instituição especializada de uma cidade do interior paulista. As entrevistas englobaram conhecimentos prévios e concepções sobre a temática, acesso à educação sexual, relacionamentos afetivos, autoimagem, prazer, etc. Os jovens entrevistados sentiam-se pouco informados sobre a temática da sexualidade e apresentaram vivências de relacionamentos que indicam vulnerabilidade e exposição a situações de riscos tanto no âmbito biológico quanto psicossocial, o que evidencia a necessidade de intervenções sobre o tema e ampliação de ações no âmbito da Educação. 
http://dx.doi.org/10.5902/1984686X48398

Em sua dissertação, Silva (2015) analisou discursos envolvidos na produção de sexualidades interpeladas como abjetas, privilegiando as intersecções entre corpo, gênero e sexualidade no contexto da gestão familiar de sujeitos narrados numa construção de anormalidade intelectual. Adotou como campo de análise as práticas sociais educativas institucionais e suas relações com os discursos/práticas da gestão familiar, em um recorte cartográfico que problematiza corpo, gênero e sexualidade dos sujeitos narrados numa construção de anormalidade intelectual no campo da saúde e educação, buscando na/da gestão familiar as construções discursivas que implicam a (in)visibilidade da sexualidade desses sujeitos no contexto da sociedade. Por meio de doze interlocutoras, identificou as construções discursivas da gestão familiar quando acionadas as práticas das experiencias da sexualidade dos/das filhos/as narrados/as numa construção de anormalidade intelectual, regularmente matriculados em um Centro de Atendimento Especializado Educacional (CAEE) em Fortaleza. A autora privilegiou leituras aproximadas dos estudos culturais e feministas, numa perspectiva desconstrucionista pós-estruturalista. Ressaltou a produção dos corpos construídos nos discursos histórico-sociais e a articulação e classificação do sujeito abjeto/monstruoso e (in)corrigível, a partir dos discursos normativos das instituições que são acionadas na gestão da sexualidade e da deficiência.

Paliarin (2015) investigou em sua pesquisa de mestrado os diversos desafios para se trabalhar com a sexualidade dentro de instituições de educação especial. Relatou a experiência em oficinas de sexualidade, realizadas em uma instituição de educação especial (APAE), para alunos em situação de deficiência intelectual, com idade entre quatorze e vinte e seis anos. Reconheceu que os obstáculos para trabalhar o tema parecem ser reforçados, principalmente pela discriminação social, considerando que pessoas com deficiência são vistas como assexuadas ou hipersexualizadas. A pesquisadora considerou a possibilidade de romper as barreiras, constatando a possibilidade de tratar a sexualidade de maneira mais espontânea em oficinas. Destacou-se ainda a necessidade de desenvolver as atividades temáticas sem os julgamentos já assimilados, para que, dadas as referências, os discentes participantes criem suas próprias ideias e concepções sobre os temas tratados.

Maia et al. (2015) investigaram em estudo descritivo, por meio de questionário para análise quali-quantitativa, a opinião de 451 professores sobre a sexualidade e a educação sexual de alunos com deficiência intelectual. $O$ interesse foi investigar 0 relato dos professores cursistas do curso "Práticas em educação especial e inclusiva, na área de 
http://dx.doi.org/10.5902/1984686X48398

deficiência mental" sobre a relação entre sexualidade e deficiência intelectual, mais especificamente suas percepções e sentimentos em relação ao alunado com deficiência intelectual. Os resultados da pesquisa revelaram ser preciso investir na formação continuada significativa em educação sexual para os professores que atuam nas escolas inclusivas.

Rosa (2016), em sua monografia, apontou a produção de conhecimento sobre a sexualidade das pessoas com deficiência intelectual e/ou Síndrome de Down no âmbito da escola a partir da aprovação do Caderno "Orientação Sexual" relativo aos PCNs. Pesquisou artigos publicados em bases de dados e analisou o material obtido mediante à técnica de análise de conteúdo temática (BARDIN, 2000). Constatou que a sexualidade das pessoas com deficiência intelectual e/ou síndrome de Down é permeada por mitos, estereótipos e conceitos ambíguos como os de assexuados e hiperssexuados. Concluiu que estas pessoas ainda enfrentam a segregação e o preconceito social da sociedade diante da manifestação da sua sexualidade na escola. Defende ser urgente a criação de programas de educação sexual que considerem as especificidades das pessoas com deficiência intelectual e/ou síndrome de Down para a diminuição dos mitos e estereótipos sobre a sexualidade desse público bem como para a efetivação de seus direitos sexuais e reprodutivos que lhes foram historicamente negados por influência de discursos baseados nos padrões normativos opressores desse grupo social.

Vieira (2016), em sua dissertação, investigou as opiniões e ações de sete mães sobre a sexualidade de seus filhos com Transtorno do Espectro Autista ou Síndrome de Asperger - TEA/SA -, com idade entre 10 e 22 anos, frequentadores de instituições de educação especial. Por meio de entrevistas, a autora concluiu que quase não há educação sexual por parte das mães: algumas se utilizam de explicações metafóricas, outras recorrem a psicólogos ou não falam sobre o assunto. Como resultado, evidenciou-se a infantilização dos filhos deficientes. A autora ressalta o direito das pessoas com TEA/SA de expressarem sua sexualidade na sociedade inclusiva e, portanto, defende a garantia do acesso à educação sexual ao longo de todo seu desenvolvimento humano.

Em sua dissertação, Pereira (2019) buscou compreender como as mulheres ditas com deficiência intelectual lidam com o corpo e a sexualidade e como os discursos acadêmicos produzem e reproduzem discursos sobre os corpos dessas mulheres. Por meio do conceito de discurso de Foucault (1996), analisou os discursos acerca da deficiência intelectual, do corpo e da sexualidade. A autora ressalta a ausência de pesquisas voltadas para pensar a 
http://dx.doi.org/10.5902/1984686X48398

relação entre corpo e sexualidade das mulheres consideradas com deficiência intelectual. Na sua pesquisa de campo, realizada em duas instituições, que abrigam mulheres ditas com deficiência intelectual, de Minas Gerais, a autora escutou mulheres consideradas com deficiência intelectual e investigou suas percepções sobre o corpo e a sexualidade. A pesquisa evidenciou que as mulheres ainda se encontram invisibilizadas, seus corpos são desconsiderados, inclusive em pesquisas que envolvem a produção de saberes sobre o tema. E que essas mulheres, apesar das dificuldades encontradas nos discursos depreciativos que envolvem a deficiência intelectual e o gênero, vêm conquistando seu espaço na sociedade, aumentando sua participação social e se impondo de diferentes maneiras.

Gonçalvez e Barbosa (2020) investigaram sobre a sexualidade de pessoas com deficiência intelectual, segundo a perspectiva de profissionais da instituição APAE de Navirai, e familiares que convivem com essa realidade. A pesquisa foi realizada com três profissionais e três responsáveis por pessoas adultas com deficiência intelectual. Os resultados indicaram que existem alguns mitos, tais como: Pessoas com deficiência são assexuadas ou hiperssexuadas, pessoas com deficiência são pouco atraentes e não conseguem usufruir o sexo normal ou ainda que, a reprodução para pessoas com deficiência é sempre problemática. A autora conclui que tais mitos não se confirmam na prática, havendo a necessidade de superação desses mitos. E que a sexualidade é a mais natural das características humanas sentidas por todos e, sendo assim, todos têm o direito de usufruí-la, inclusive as pessoas que têm deficiência intelectual.

\section{Discursos de verdade e a produção do corpo da mulher dita com deficiência intelectual}

A despeito dos limites do Estado da arte que analisa pesquisas por meio de seus resumos, notamos que o discurso científico reitera posições estereotipadas e invisibiliza os corpos e a sexualidade da mulher considerada com deficiência intelectual. As pesquisas acadêmicas localizadas nos bancos de dados acerca da deficiência intelectual reforçam os estereótipos de cunho depreciativo arraigados pela sociedade. A maior parte desses trabalhos reproduzem discursos que reforçam concepções de que esse grupo permanece estagnado em um lugar de passividade, opressão, incapaz de romper com os regimes de verdades da sociedade. 
http://dx.doi.org/10.5902/1984686X48398

Algumas produções acadêmicas, por meio dos discursos de verdades, (re)produzem os corpos das mulheres consideradas com deficiência intelectual, de forma estereotipada, mantendo-as no lugar de vítimas, não destacando suas potencialidades, e, assim, pouco contribuem para o avanço teórico no campo, nem tampouco para o empoderamento dessas mulheres.

Ressaltamos a insuficiência de estudos que investiguem a resistência, a superação e o potencial das mulheres ditas com deficiência intelectual nas pesquisas acerca do corpo, da sexualidade e da deficiência intelectual. O Estado da arte mostrou que alguns discursos acadêmicos (re)produzem os corpos e a sexualidade dessas mulheres mantendo esses corpos enclausurados e aniquilados. As produções teóricas e acadêmicas que produzem essas mulheres e seus corpos estariam mantendo e reforçando o lugar de seres abjetos?

Algumas dessas pesquisas demonstram ser imprescindível a formação dos profissionais e familiares, a fim de tomarem atitudes coerentes ao se depararem com manifestações de sexualidade de alunos(as) ou filhos(as) ditos com deficiência. Estudos como o de Pieczkowski (2007), Almeida (2010) e Oliveira (2014) indicam que, para a pessoa com deficiência mental/intelectual, as barreiras encontradas para vivenciarem a sexualidade não são de ordem biológica, mas sim adaptativa.

Esses estudos indicam que ainda há um preconceito implícito, em se tratando do lugar do sujeito com deficiência intelectual na sociedade, sendo possível destacar atitudes coercitivas e certo descaso quanto aos seus sentimentos, infantilizando ou exacerbando sua maneira de lidar com o corpo e a sexualidade. Estudos como o de Bastos (2005), Littig et al. (2012) e Oliveira (2012) destacam que sujeitos com deficiência intelectual são vistos como assexuados ou, em outro extremo, como hipersexualizados.

Outros desses trabalhos destacam a forma de ver a deficiência como uma tragédia, ressaltando que os discursos sociais acerca da pessoa considerada com deficiência intelectual a julgam como incapaz de fazer suas escolhas, ainda que relacionadas ao próprio corpo. Destacam ainda que a sexualidade na sociedade não é compreendida para além dos contornos biológico-reprodutivo e não alcança o campo da afetividade, da demonstração de sentimento e de experiências compartilhadas.

Em nossa pesquisa, consideramos que os corpos das mulheres com deficiência intelectual são considerados corpos abjetos. Os corpos considerados abjetos pela norma estão desconstituídos de sua humanidade e, por isso, são relegados à invisibilidade, segundo Butler (2003). O abjeto não se restringe de modo algum a sexo e 
http://dx.doi.org/10.5902/1984686X48398

heteronormatividade: "Relaciona-se a todo tipo de corpos cujas vidas não são consideradas 'vidas' e cuja materialidade é entendida como não importante” (BUTLER, 2003, p. 161). Butler (2010) nomeia de abjetos os que ocupam zonas inóspitas e inabitáveis da vida social. Os abjetos não gozam do status de sujeito, mas seu habitar sob o signo do inabitável é preciso para marcar o domínio do sujeito. Estariam os corpos das mulheres consideradas com deficiência intelectual distantes de tais zonas inóspitas?

Segundo Butler (2010), a reconstituição dos corpos introduz a dinâmica do poder que denuncia a indissociabilidade entre a matéria dos corpos e as normas regulatórias que governam a materialização e significação dos seus efeitos. A construção do sexo não é mais encarada como um dado corporal sobre o qual o constructo do gênero é artificialmente imposto, e sim como uma norma cultural que governa e materializa os corpos. Em outras palavras, os seres humanos são (re)constituídos por meio dos discursos, saberes e verdades dos ambientes sociais que os cercam (BUTLER, 2010).

Os discursos produzem saberes e o saber é poder, assim, ao desconsiderar as potencialidades dessas mulheres, algumas pesquisas acadêmicas contribuem para a cristalização dos estereótipos presentes em nossa sociedade, que ainda inferiorizam e distanciam os corpos desse grupo de mulheres.

Concordamos com Foucault (1993), que o poder é ação que produz sujeitos e coisas o tempo todo, além de produzir arenas de disputa; e são nessas arenas de disputa que se desenham quem é o oprimido e quem é o opressor. O poder está nas relações sociais, assim sendo, as mulheres consideradas com deficiência intelectual também exercem poder no contexto onde se encontram. A escassez de estudos com foco no potencial da mulher dita com deficiência intelectual evidencia que o poder exercido por tais mulheres tem sido esquecido pela maioria das pesquisas localizadas no Estado da arte. Compreendemos que o poder circula e todos exercem poder, o que não é diferente para as mulheres consideradas com deficiência intelectual.

Segundo Foucault (1993), o poder não deve ser entendido como uma entidade ou como uma ideia ou identidade teórica. Em vez disso, deve ser entendido como prática ou como exercício, que só existe em sua materialidade, realizado em níveis diversificados e em múltiplas direções no cotidiano, por meio de instituições como a escola, a prisão, o hospício, o quartel, a fábrica, os meios de comunicação e as ciências.

Onde há poder, há também resistência, por isso, essa nunca é externa em relação ao poder. Devemos admitir que se viva absolutamente no poder, já que dele não se foge. 
http://dx.doi.org/10.5902/1984686X48398

Foucault (1993) defende que as relações de poder existem em função de uma variedade de pontos de resistência que representam a correlação de poder, a figura de opositor, de alvo, de suporte, de evidência que permite a apreensão.

\section{Conclusão}

Notamos nesses trabalhos de investigação acerca da deficiência intelectual e sua relação com o corpo e sexualidade a importância de realinhar os discursos e representações tanto nas práticas educacionais e cotidianas, quanto nas próprias pesquisas acadêmicas, levando-se em conta que o sujeito dito com deficiência intelectual deve compreender melhor questões relacionadas ao corpo e à sexualidade, especialmente mulheres nessa condição, compreendendo a sexualidade como tema central de nossa existência.

As pesquisas apresentadas apontam discussões genéricas acerca das pessoas com deficiência, em relação aos seus corpos, gêneros e sexualidades. Algumas delas destacam a deficiência mental ou intelectual nessa relação, mas em sua maioria evidenciam a carência de discussões específicas sobre mulheres com deficiência intelectual, e quando aparecem denunciam os poucos espaços para as mulheres consideradas deficiente intelectual relatarem suas dúvidas, curiosidades e anseios. Ajudam-nos a interrogar 0 paradoxo com relação à sexualidade, ao constatarmos que a sociedade ora reconhece a pessoa dita com deficiência intelectual como assexuada, ora a julga como hipersexuada.

Além desse aspecto, nas pesquisas encontradas, são destacadas as concepções preconceituosas do senso comum que ainda predominam com relação à sexualidade das pessoas ditas com deficiência intelectual, tais como: "são desinteressantes, despreparadas, indefesas e incapazes de vivenciar o sexo de maneira natural". Esses trabalhos destacam compreensões de que a reprodução dessas mulheres é problemática, consideram-nas estéreis, geradoras de filhos com deficiência ou ainda sem condições de exercer o papel de mãe. Tais crenças revelam os discursos preconceituosos que compreendem a sexualidade dessas mulheres como desviantes dos padrões definidores de normalidade. $O$ foco em tais reproduções é um modo de dificultar a superação da discriminação social e sexual que prejudica os ideais de uma sociedade inclusiva.

As pesquisas evidenciam que os obstáculos para trabalhar com a educação sexual nas instituições parecem ainda tender para o viés biologizante, sendo reforçados principalmente pelos discursos de verdade, os quais consideram que pessoas ditas com 
http://dx.doi.org/10.5902/1984686X48398

deficiência intelectual são assexuadas ou hipersexualizadas. Porém, algumas dessas pesquisas reiteram a necessidade de romper com as dificuldades de tratar o tema sexualidade, tornando os assuntos relacionados à Educação Sexual mais espontâneos, evitando assim a transmissão de informações que nem sempre estão claras e possibilitando a esses sujeitos mais compreensão do seu corpo e da sua sexualidade.

Para finalizar, em nossa pesquisa reiteramos que as mulheres consideradas com deficiência intelectual nem sempre são frágeis, muitas se impõem. Contudo, ainda são fragilizadas em diversos discursos, inclusive acadêmicos, embora singularmente, muitas refutam esse lugar de subalternidade por muito tempo lhes reservado.

\section{Referências}

ALBUQUERQUE, Paloma Pegolo. A sexualidade como aspecto inclusivo: uma proposta de intervenção para pais e professores de Jovens com Deficiência Mental. Dissertação (Mestrado em Educação Especial) - Universidade Federal de São Carlos, Centro de Educação e Ciências Humanas, São Carlos, 2007.

ALMEIDA, Paula Alexandra Camelo. A sexualidade na Deficiência Mental. Saber \& Educar, Porto, n. 15, p. 01-09, 2010. Disponível em: https://revista.esepf.pt/index.php/sabereducar/article/view/96. Acesso em 14 jul. 2020.

AMARAL, Mariana Clivati. Sexualidade e deficiência mental: impacto de um programa de orientação para famílias. Dissertação (Mestrado em Educação Especial) - Universidade Federal de São Carlos, Centro de Educação e Ciências Humanas, São Carlos, 2004.

BARBOSA, Jaqueline Almeida Guimarães. Sexualidade e vulnerabilidade social de pessoas com transtornos mentais atendidas em serviços públicos de saúde mental no Brasil. Tese (Doutorado em Enfermagem) - Universidade Federal de Minas Gerais, Escola de Enfermagem, Belo Horizonte, 2011.

BARROS, Roberta Dias; WILLIAMS, Lúcia Cavalcanti de Albuquerque; BRINO, Rachel de Faria. Habilidades de autoproteção acerca do abuso sexual em mulheres com deficiência mental. Revista Brasileira de Educação Especial, Marília, v. 14, n. 1, p. 93-110, 2008.

BASTOS, Olga Maria. Entre o desejo e o medo de ver o filho adolescer: narrativas de pais de adolescentes com deficiência mental. Tese (Doutorado em Saúde da Criança e da Mulher) - Fundação Oswaldo Cruz, Instituto Fernandes Figueira, Rio de Janeiro, 2005.

BASTOS, Olga Maria; DESLANDES, Suely Ferreira. Sexualidade e o adolescente com deficiência mental: uma revisão bibliográfica. Ciência \& Saúde Coletiva, Rio de Janeiro, v. 10, n. 2, p. 389-397, abr./jun 2005. Disponível em: https://www.scielo.br/pdf/csc/v10n2/a17v10n2.pdf. Acesso em 12 maio 2020. 
http://dx.doi.org/10.5902/1984686X48398

BROGNA, P. Visiones y revisiones de la discapacidad. México: FCE, 2009.

BUTLER, Judith. Problemas de gênero: feminismo e subversão da identidade. Rio de Janeiro: Civilização Brasileira, 2003.

CASTELÃO, Talita Borges; SHIAVO, Márcio Ruiz; JURBERG, Pedro. Sexualidade da pessoa com síndrome de Down. Revista de Saúde Pública, São Paulo, v. 37, n.1, p. 3239, 2003. Disponível em: https://www.scielo.br/pdf/rsp/v37n1/13542.pdf. Acesso em 10 maio 2020.

DANTAS, Taísa Caldas; SILVA, Jackeline Susann Souza; CARVALHO, Maria Eulina Pessoa. Entrelace entre gênero, sexualidade e deficiência: uma história feminina de rupturas e empoderamento. Revista Brasileira de Educação Especial, Marília, v. 20, n. 4, p. 555-568, out./dez. 2014. Disponível em:

https://www.scielo.br/pdf/rbee/v20n4/a07v20n4.pdf. Acesso em 11 maio 2020.

DINIZ, Débora. O que é deficiência. São Paulo: Brasiliense, 2007.

FERREIRA, Norma Sandra. As pesquisas denominadas "estado da arte". Educação \& Sociedade, ano XXIII, v. 23, no 79, p. 257-272, agos /2002. Disponível em: https://www.scielo.br/pdf/es/v23n79/10857.pdf. Acesso em 14 jul. 2020.

FOUCAULT, Michel. História da sexualidade humana I: a vontade de saber. 11. ed. Rio de Janeiro: Graal, 1993 [1976].

FOUCAULT, Michel. História da sexualidade III: o cuidado de si. Rio de Janeiro: Edições Graal, 1985 [1984].

GAUDENZI, P.; ORTEGA, F. Problematizando o conceito de deficiência a partir das noções de autonomia e normalidade. Ciência \& Saúde Coletiva, Rio de Janeiro, v. 21, n. 10, p. 3068-3070, 2016. Disponível em:

http://dx.doi.org/10.1590/1413812320152110.16642016. Acesso em 20 jun. 2018.

GIAMI, Alain. O anjo e a fera: sexualidade, deficiência mental, instituição. São Paulo: Casa do Psicólogo, 2004.

GLAT, Rosana. Somos iguais a vocês: depoimentos de mulheres com deficiência mental. Rio de Janeiro: Agir, 1989.

GOFFMAM, Erving. Estigma: notas sobre manipulação da identidade deteriorada. Rio de Janeiro: Guanabara, 1988.

GONÇALVES, Josiane Peres; Barbosa, Maria Madalena Freitas. Opiniões de mães e profissionais sobre a sexualidade de pessoas com deficiência intelectual. Revista Exitus, Santarém/PA, V. 10, p. 01-30, 2020. Disponível em: https://doi.org/10.24065/22379460.2020v10n0ID1143. Acesso em 06 set. 2020. 
LITTIG, Patrícia Matos Caldeira Brant. et al. Sexualidade na deficiência intelectual: uma análise de percepções de mães de adolescentes especiais. Revista Brasileira de Educação Especial, Rio de Janeiro, v. 18, n. 3, p. 469-486, set. 2012. Disponível em: https://www.scielo.br/pdf/rbee/v18n3/a08.pdf. Acesso em 12 maio 2020.

LOURO, Guacira Lopes. O corpo educado: pedagogias da sexualidade. 3 ed. Belo Horizonte: Autêntica Editora, 2010.

LÜDKE, Menga; ANDRÉ, Marli. E. A Pesquisa em Educação: abordagens qualitativas. São Paulo: Editora Pedagógica e Universitária Ltda., 2003.

LUIZ, Elaine Cristina; KUBO, Olga Mitsue. Percepções de jovens com Síndrome de Down sobre relacionar-se amorosamente. Revista Brasileira de Educação Especial, Bauru, v. 13, n. 2, p. 219-238, maio/ago. 2007. Disponível em:

https://www.scielo.br/scielo.php?script=sci_abstract\&pid=S141365382007000200006\&lng =es\&nriso\&tlng=pt. Acesso em 13 maio 2020.

MAIA, Ana Cláudia Bortolozzi. et al. Opinião de professores sobre a sexualidade e a educação sexual de alunos com deficiência intelectual. Estudos de Psicologia I, Campinas, v. 32, n. 3, p. 427-435, jul./set. 2015. Disponível em:

https://www.scielo.br/scielo.php?pid=S0103166X2015000300427\&script=sci_arttext. Acesso em 09 maio 2020.

MIRANDA, Francisco Arnaldo Nunes; FUREGATO, Antonia Regina Ferreira; AZEVEDO, Dulcian Medeiros. Práticas discursivas e o silenciamento do doente mental: sexualidade negada? Escola Anna Nery Revista Enfermagem, Rio de Janeiro, v. 12, n. 1, p. 136142, mar. 2008.

MORALES, Aida Souza. Apropriação de práticas sociais relativas à sexualidade por jovens adultos com diagnóstico de deficiência intelectual. Dissertação (Mestrado em Pediatria) - Universidade Estadual de Campinas, Faculdade de Ciências Médicas, 2008.

OLIVEIRA, Julian Simões Cruz de. Assexuados, libidinosos ou um paradoxo sexual? Gênero - e sexualidade em pessoas com deficiência intelectual. Dissertação (Mestrado em antropologia Social) - Universidade Federal de Campinas, Instituto de Filosofia e Ciências Humanas, Campinas, 2014.

PALIARIN, Franciely. Sexualidade e deficiências: dando vozes aos adolescentes por meio de oficinas pedagógicas. Dissertação (Mestrado Profissional em Educação Sexual). Universidade Estadual Paulista "Júlio de Mesquita Filho", Faculdade de Ciências e Letras, Araraquara, 2015.

PEREIRA, Alcilene. Mulheres ditas com deficiência intelectual: Limites e possiblidades dos contextos inclusivos. Dissertação (Mestrado em Educação) - Universidade Federal de Ouro Preto, Instituto de Ciências Humanas e Sociais, Mariana, 2019.

PESSOTTI, Isaías. Deficiência mental: da superstição à ciência. São Paulo: EDUSP, 1984. 
http://dx.doi.org/10.5902/1984686X48398

PIECZKOWSKI, Tania Mara Zancanaro. Educação sexual de pessoas com deficiência mental. Revista Educação Especial, Santa Maria, n. 30, p. 1-8, nov. 2007. Disponível em: https://periodicos.ufsm.br/educacaoespecial/article/view/4086. Acesso em 04 maio 2020.

PINHEIRO, Silvia Nara Siqueira. Sexualidade e deficiência mental: revisando pesquisas. Psicologia Escolar e Educacional, Campinas, v. 8, n. 2, p. 199-206. 2004. Disponível em: http://dx.doi.org/10.1590/S1413-85572004000200008. Acesso em 10 mai. 2019.

RÉGIS, Hebe Cristina Bastos. Mulheres com deficiência intelectual e a esterilização involuntária. De quem é esse corpo? Dissertação (Mestrado em Psicologia) Universidade Federal de Santa Catarina, Programa de Pós-Graduação em Psicologia, Florianópolis, 2013.

RIOS, Clarice. "Nada sobre nós, sem nós"? O corpo na construção do autista como sujeito social e político. Sexualidad, Salud y Sociedad, Rio de Janeiro, n. 25, p. 212-230, abr. 2017. Disponível em:

http://www.scielo.br/scielo.php?script=sci_arttext\&pid=S19864872017000100212\&lng=en \&nrm=iso. Acesso em: 22 fev. 2020.

ROSA, Maria de Fátima da. Produção do conhecimento sobre sexualidade e deficiência intelectual e/ou síndrome de down. Monografia (Especialização)- Universidade Federal de Santa Catarina, Centro de Filosofia e Ciências Humanas, Florianópolis, SC, 2016.

SANTOS, Myrna Wolff Brachmann. Sexualidade da pessoa com deficiência mental: entre discursos de verdade e a possibilidade de outras práticas de si. Dissertação (Mestrado em Educação) - Universidade Federal de Mato Grosso do Sul, Centro de Ciências Humanas e Sociais, Campo Grande, 2007.

SANTOS, Myrna Wolff Brachmann; OSÓRIO, Antônio Carlos do Nascimento. Saber e prática na constituição da sexualidade da pessoa com deficiência mental. 2010. Revista Educação Especial, Santa Maria, v. 23, n. 36, p. 117-130, jan./abr. 2010 Disponível em: https://periodicos.ufsm.br/educacaoespecial/article/view/1437. Acesso em: 12 jul. 2020.

SASSAKI, Romeu Kasumi. Atualizações semânticas na inclusão de pessoas: Deficiência mental ou intelectual? Doença ou transtorno mental? Revista Nacional de Reabilitação, São Paulo, ano IX, n. 43, p. 9-10, mar./abr. 2005. Disponível em:

http://www.pcd.mppr.mp.br/arquivos/File/ArtigoDeficiencia_mental_ou_intelectual.pdf. Acesso em 3 maio 2020.

SILVA, Sandra Maria Alexandre. Cartografando a Gestão Familiar do Sujeito Narrado em uma Construção de Anormalidade Intelectual: intersecções entre Gênero, Sexualidade e "Deficiência". Dissertação (Mestrado em Psicologia) - Universidade de Fortaleza, Programa de Pós-Graduação em Psicologia Fortaleza, 2015.

SODELLI, Fernanda Guilard. Questões invisíveis e as histórias contadas por jovens: deficiência intelectual e vulnerabilidade ao hiv/aids. Dissertação (Mestrado em Distúrbio do Desenvolvimento) - Universidade Presbiteriana Mackenzie, Centro de Ciências Biológicas e da Saúde, São Paulo, 2010. 
SOUZA, Marina Celly Martins Ribeiro. Representações de profissionais da saúde mental sobre sexualidade de pessoas com transtornos mentais. Tese (Doutorado em Enfermagem) - Universidade Federal de Minas Gerais, Escola de Enfermagem, Belo Horizonte, 2014.

TEIXEIRA, Gustavo. Manual dos transtornos escolares: entendendo os problemas de crianças e adolescentes na escola". 5 ed. Rio de Janeiro: BestSeller, 2014.

UZÊDA, Sheila de Quadros. Identidade feminina e sexualidade na concepção de mulheres com Síndrome de Down: educação sexual como caminho para a construção de maior autonomia. Salvador. Dissertação (Mestrado em Educação) - Universidade Federal da Bahia, Faculdade de Educação, 2006.

VIEIRA, Ana Carla. Sexualidade e transtorno do espectro autista: relatos de familiares.

Dissertação (Mestrado em Psicologia do Desenvolvimento e Aprendizagem) - Universidade Estadual Paulista Júlio de Mesquita Filho, Faculdade de Ciências, Bauru, 2016.

VIEIRA, Camila Mugnai. Coelho, Marili André. Sexualidade e deficiência intelectual: concepções, vivências e o papel da educação. Revista Tempos e Espaços em Educação, 201-212. https://doi.org/10.20952/revtee.v0i0.3268. Acesso em 06 set. 2020.

ZEOTI, Fernanda Saviani. A qualidade de vida de adultos com deficiência mental leve, na percepção destas pessoas e na de seus cuidadores. Dissertação (Mestrado em Ciências) - Universidade de São Paulo, Faculdade de Filosofia, Ciências e Letras, 2005.

\title{
Notas
}

\begin{abstract}
${ }^{1}$ Neste trabalho estamos sendo fiéis aos termos utilizados nos trabalhos localizados no Estado da arte. Contudo, ressaltamos que em 1995 a Organização das Nações Unidas - ONU alterou o termo deficiência mental para deficiência intelectual, com o objetivo de diferenciá-la da doença mental (transtornos mentais que não necessariamente estão associados ao déficit intelectual). A pessoa com deficiência intelectual caracteriza-se por ter um funcionamento intelectual significativamente inferior à média, acompanhado de limitações significativas no funcionamento adaptativo em pelo menos duas das seguintes áreas de habilidades: comunicação, autocuidados, vida doméstica, habilidades sociais/interpessoais, uso de recursos comunitários, autossuficiência, habilidades acadêmicas, trabalho, lazer, saúde e segurança (Fonte: http://www.institutoparadigma.org.br).
\end{abstract}

\section{Correspondência}

Alcilene Rodrigues Pereira - Rua José Raimundo Figueiredo, Número 280, Bairro São Cristóvão, Mariana, Minas Gerais- Brasil.

CEP: $35.420-000$

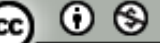

International (CC BY-NC 4.0) 